\title{
Expanding the molecular toolbox for Lactococcus lactis: construction of an inducible thioredoxin gene fusion expression system
}

François P Douillard ${ }^{1,4}$, Mary O'Connell-Motherway ${ }^{1,2}$, Christian Cambillau ${ }^{3}$ and Douwe van Sinderen ${ }^{1,2^{*}}$

\begin{abstract}
Background: The development of the Nisin Inducible Controlled Expression (NICE) system in the food-grade bacterium Lactococcus lactis subsp. cremoris represents a cornerstone in the use of Gram-positive bacterial expression systems for biotechnological purposes. However, proteins that are subjected to such over-expression in L. lactis may suffer from improper folding, inclusion body formation and/or protein degradation, thereby significantly reducing the yield of soluble target protein. Although such drawbacks are not specific to L. lactis, no molecular tools have been developed to prevent or circumvent these recurrent problems of protein expression in L. lactis.
\end{abstract}

Results: Mimicking thioredoxin gene fusion systems available for $E$. coli, two nisin-inducible expression vectors were constructed to over-produce various proteins in L. lactis as thioredoxin fusion proteins. In this study, we demonstrate that our novel L. lactis fusion partner expression vectors allow high-level expression of soluble heterologous proteins Tuc2009 ORF40, Bbr_0140 and Tuc2009 BppU/BppL that were previously insoluble or not expressed using existing L. lactis expression vectors. Over-expressed proteins were subsequently purified by Ni-TED affinity chromatography. Intact heterologous proteins were detected by immunoblotting analyses. We also show that the thioredoxin moiety of the purified fusion protein was specifically and efficiently cleaved off by enterokinase treatment.

Conclusions: This study is the first description of a thioredoxin gene fusion expression system, purposely developed to circumvent problems associated with protein over-expression in L. lactis. It was shown to prevent protein insolubility and degradation, allowing sufficient production of soluble proteins for further structural and functional characterization.

Keywords: nisin, thioredoxin, expression system, Lactococcus lactis

\section{Background}

The food-grade bacterium L. lactis subsp. cremoris in conjunction with the Nisin Inducible Controlled Expression (NICE) system [1-3] has been extensively used over the last few decades as a valuable bacterial expression system for large-scale production of homologous or heterologous proteins [4], metabolic studies [5], or membrane proteins [6]. The NICE system is based on the well characterized nisin-dependent, quorum-sensing mechanism of L. lactis $[2,3,7]$. It was initially exploited

\footnotetext{
* Correspondence: d.vansinderen@ucc.ie

'Department of Microbiology, University College Cork, Cork, Ireland

Full list of author information is available at the end of the article
}

in L. lactis for heterologous protein overexpression and subsequently implemented in several other Gram-positive bacteria $[2,3,7-10]$. Typically, the genetically-engineered strain L. lactis subsp. cremoris NZ9000 is employed as expression host, as its chromosome contains the signal transduction genes nisR and nisK involved in the nisin-induced transcriptional control of the PnisA promoter [3]. Any genes cloned downstream this nisin-inducible promoter Pnis $A$ can be expressed in a controlled manner upon addition of nisin to the bacterial culture [3]. However, production of recombinant proteins can be problematic in L. lactis, as overexpressed proteins may be subject to poor expression,
C Biomed Central

(ㄷ) 2011 Douillard et al; licensee BioMed Central Ltd. This is an Open Access article distributed under the terms of the Creative Commons Attribution License (http://creativecommons.org/licenses/by/2.0), which permits unrestricted use, distribution, and reproduction in any medium, provided the original work is properly cited. 
stability and/or solubility. Such drawbacks are intrinsically associated with the prokaryotic cell machinery limitations and therefore are inherent to all bacterial expression systems, representing a significant bottleneck in high level production of soluble proteins.

In E. coli, a 'microbial cell factory' of choice for producing heterologous proteins [11,12], the development of the gene fusion technology proved to circumvent such recurrent and fundamental protein expression problems [13]. This technology involves the linkage of the protein of interest with a carrier protein to generate a fusion protein. Addressing solutions to problematic protein expressions, many fusion expression systems have been engineered and successfully employed, using solubility-enhancing fusion partners such as Schistosoma japonicum glutathione-Stransferase (GST) [14], E. coli maltose binding proteins (MBP) [15], Staphylococcus protein A [16], E. coli N-utilization substance (NusA) [17] and E. coli thioredoxin (TrxA) $[18,19]$. Along with the increasing number of fusion partners used, additional features have been successfully implemented to this technology, thus facilitating protein tagging, purification techniques and tag-mediated proteolytic cleavage $[13,20,21]$. The gene fusion technology provides a substantial palette of applications through the constant expansion of fusion gene expression systems available in E. coli. Nevertheless, the adaptation of these existing fusion partner systems to other expression hosts is sparse, even though significant progress has been made to develop new molecular tools and methods in alternative prokaryotic and eukaryotic expression systems [1,22,23]. The expression host $L$. lactis is currently lacking such a solubility-enhancing expression system to improve its spectrum of biotechnological applications, as $L$. lactis featured a number of benefits over other expression bacterial hosts, $e$. $g$. being a food-grade expression host, and the absence of endotoxins, extracellular proteinases and spores.

As part of our study on the structure-function analysis of lactococcal phage-host recognition and penetration, we attempted to over-express a number of proteins encoded by the lactococcal phage Tuc2009 in L. lactis. However, initial expression studies of individual protein subunits of Tuc2009 phage revealed such proteins often suffer from degradation, poor expression or result in insoluble protein aggregates, also called inclusion bodies (data not shown). The development of a fusion-based gene expression system in L. lactis could provide a novel strategy to express soluble proteins and avoid the use of laborious and spurious renaturation procedures. Among the numerous fusion partners employed, LaVallie et al. described the construction of an E. coli thioredoxin (TrxA) gene fusion system [19]. In most cases, $E$. coli thioredoxin fusion proteins were soluble, correctly folded and biologically active [19]. The E. coli thioredoxin thus appears to represent a good candidate for an
L. lactis fusion-based gene expression system: small size of the fusion partner $(11.67 \mathrm{kDa})$, ability to accumulate in a soluble form at high levels in the cytoplasm, steric accessibility of $\mathrm{N}$ - and $\mathrm{C}$-termini of TrxA for protein fusions [19] and efficient generic protein purification methods available, i.e. immunoprecipitation or affinity chromatography [13,24].

In the present study, we report on the construction of two new L. lactis thioredoxin-fusion gene expression vectors harbouring the nisin-controlled expression (NICE) system. We evaluated the efficiency of the newly-constructed fusion gene expression system, by producing individual proteins or protein complexes that initially could not be expressed or were not soluble in $L$. lactis. Our data indicate that the L. lactis thioredoxinfusion vectors represent a very valuable addition to the L. lactis genetic toolbox, in particular for the over-production of soluble proteins.

\section{Methods}

\section{Bacterial strains, media, growth conditions and nisin} preparation

Bacterial strains described in this study are listed in Table 1. L. lactis subsp. cremoris NZ9000 [3] and NZ9700 [3,6,7] were cultured at $30^{\circ} \mathrm{C}$ under static conditions in GM17 broth (M17 broth [25]; Oxoid, UK) with $0.5 \%(\mathrm{w} / \mathrm{v}) \mathrm{D}$-glucose (Sigma)). L. lactis transformants were selected on GM17 agar plates supplemented with $5 \mu \mathrm{g} / \mathrm{ml}$ chloramphenicol (Sigma). The supernatant from overnight cultures of the nisin-producing strain $L$. lactis NZ9700 was filter-sterilized and used in this study as a source of the inducer nisin [6].

\section{DNA amplification and cloning}

Oligonucleotide primers were purchased from Eurofins MWG GmbH (Germany) and are listed in Table 2. Genomic DNA from Tuc2009 or B. breve UCC2003 was extracted as previously described [26,27]. Plasmids and primers are listed in Tables 1 and 2, respectively. High-fidelity hot start KOD DNA polymerase (Novagen, UK), restriction enzymes (Roche GmbH, Germany) and T4 DNA ligase (Promega, USA) were used as recommended by the relevant manufacturers. Plasmid DNA was electroporated into L. lactis NZ9000 as described by Holo et al. [28].

\section{Construction of thioredoxin gene fusion expression vectors}

The two expression vectors constructed in this study, called pTX8048 and pTX8049, are derived from the high-copy number vector pNZ8048 harbouring the NICE system and a chloramphenicol resistance marker [3]. The high-copy number expression vector pTX8048 was constructed as follows. The DNA fragment containing the E. coli $\operatorname{trx} A$ gene was amplified from the 
Table 1 Bacterial strains and plasmids used in this study

\begin{tabular}{lll}
\hline Strains or plasmids & Relevant characteristics & Reference or source \\
\hline $\begin{array}{l}\text { Strains } \\
\text { L. lactis }\end{array}$ & & [3] \\
NZ9000 & MG1363 containing nisRK genes, & {$[3,7]$} \\
NZ9700 & Nisin producing L. lactis strain & [3] \\
Plasmids & & This study \\
pNZ8048 & Standard L. lactis expression vector, Cm r & This study \\
pTX8048 & pNZ8048 derivative harbouring the TrXA system, contains a His-tag cloned in frame & This study \\
pTX8049 & pNZ8048 derivative harbouring the TrXA system & This study \\
pNZ8048-UAL & pNZ8048 encoding Tuc2009 bppU, bppA, bppL as an operon & This study \\
pTX8048-UAL & pTX8048 encoding Tuc2009 bppU, bppA, bppL as an operon & This study \\
pNZ8048-40 & pNZ8048 encoding Tuc2009 orf40 & This study \\
pTX8048-40 & pTX8048 encoding Tuc2009 orf40 & This study \\
pNZ8048-0140N & pNZ8048 encoding N-terminal His-tagged Bbr_0140 & This study \\
pNZ8048-0140C & pNZ8048 encoding C-terminal His-tagged Bbr_0140 &
\end{tabular}

$\mathrm{Cm}$, chloramphenicol.

Table 2 Oligonucleotide primers used in this study

\begin{tabular}{|c|c|c|}
\hline Primer & Sequence $\left(5^{\prime}-3^{\prime}\right)$ & Comments \\
\hline $\begin{array}{l}\text { pTX48- } \\
F\end{array}$ & AGCCCATGGGCGATAAAATTATTCACCTGACT & Forward primer of trxA \\
\hline $\begin{array}{l}\mathrm{pTX} 48- \\
\mathrm{R}\end{array}$ & AGCCTGCAGGATCCCTTGTCGTCGTCGTCACCAGAAGAATGATGATGATGATGGTGCATATGGCCAGAAC & $\begin{array}{l}\text { Reverse primer of trxA flanked by an } \\
\text { enterokinase cleavage site and a His-tag }\end{array}$ \\
\hline $\begin{array}{l}\text { pTX49- } \\
\mathrm{R}\end{array}$ & AGCCTGCAGGATCCCATATGGCCAGAACCAGAAC & Reverse primer of $\operatorname{tr} x A$ \\
\hline UAL-F & AGCAGCCATGGCAGAACATTITATAAC & Forward primer of bppU for pNZ8048 \\
\hline UAL-R & AGCAGCACTAGTTTAGTGATGGTGATGGTGATGATTCCGATAAAGTTTACAATC & Reverse primer of $b p p L$ for $p N Z 8048$ \\
\hline $\begin{array}{l}\text { UALX- } \\
F\end{array}$ & AGCAGCGGATCCATGACAGAACATTITATAAC & Forward primer of bpp U for pTX8048 \\
\hline $\begin{array}{l}\text { UALX- } \\
\text { R }\end{array}$ & AGCAGCACTAGTTIAATTCCGATAAAGTTTTACAATC & Reverse primer of $b p p L$ for $p T X 8048$ \\
\hline orf40-F & AGCAGCCCATGGGGCGGCTACTAAGTCGCCACTTGCATAAAT & Forward primer of orf40 for pNZ8048 \\
\hline orf40-R & AGCAGCACTAGTTAGTGATGGTGATGGTGATGTAAGTGATAGCCATAAGCAA & Reverse primer of orf40 for pNZ8048 \\
\hline $\begin{array}{l}\text { orf40X- } \\
\text { F }\end{array}$ & AGCAGCGGATCCATGGGGCGGCTACTAAGTCGCCACTTGCATAAAT & Forward primer of orf40 for pTX8048 \\
\hline $\begin{array}{l}\text { orf40X- } \\
R\end{array}$ & AGCAGCACTAGTTITAAAGTGATAGCCATAAGCAA & Reverse primer of orf 40 for $\mathrm{pTX} 8048$ \\
\hline $\begin{array}{l}0140 N- \\
F\end{array}$ & TGCATCCCATGGATCATCACCATCACCATCACCATCACCATCACAGCCGGATTCTCAAGGAC & $\begin{array}{l}\text { Forward primer of bbr_0140 for } \\
\text { pNZ8048 }\end{array}$ \\
\hline $\begin{array}{l}0140 N- \\
R\end{array}$ & TGCGCATCTAGATTATGCGATGTAGCTTTC & Reverse primer of orf40 for pNZ8048 \\
\hline $\begin{array}{l}0140 C- \\
F\end{array}$ & AATTAACCATGGGCCGGATTCTCAAGGACAAGC & $\begin{array}{l}\text { Forward primer of bbr_0140 for } \\
\text { pNZ8048 }\end{array}$ \\
\hline $\begin{array}{l}0140 C- \\
R\end{array}$ & TGCCGTICTAGATTAGTGATGGTGATGGTGATGGTGATGGTGATGTGCGATGTAGCTTTCGATGTGTAG & Reverse primer of bbr_0140 for pNZ8048 \\
\hline $\begin{array}{l}0140 X- \\
F\end{array}$ & GACAAGGGATCCATGAGCCGGATTCTCAAG & Forward primer of bbr_0140 for pTX8048 \\
\hline $\begin{array}{l}\text { 0140X- } \\
\mathrm{R}\end{array}$ & AGCTCTCTAGATTATGCGATGTAGCTTTC & Reverse primer of bbr_0140 for pTX8048 \\
\hline
\end{tabular}

In italic font, are indicated the sequencer encoding enterokinase cleavage site. In bold font, are indicated the polyhistidine tag-encoding sequence. The restriction sites are underlined. 
Gateway ${ }^{\circledR}$ plasmid pETG-20a and flanked with a polyhistidine tag and an enterokinase cleavage site by PCR using primers pTX48-F and pTX48-R (Table 2). The resulting DNA amplicon was double-digested by NcoI and PstI, and then ligated to the similarly digested pNZ8048 plasmid (Figure 1). The ligation product was transformed into L. lactis NZ9000 and screened by colony PCR, and verified by restriction and sequencing analyses. The plasmid pTX8049 was constructed following a similar cloning strategy using primers pTX48-F and pTX49-R (Figure 1 and Table 2).

\section{Construction of expression vectors encoding thioredoxin fusion proteins}

The gene encoding the Tuc2009 phage protein Tuc2009 ORF40 [29] was amplified from Tuc2009 DNA and flanked with a C-terminal hexa-histidine tag using primers orf40-F and orf40-R. The PCR product was digested with NcoI and SpeI and then ligated to pNZ8048 cut with NcoI and SpeI. The ligation product was transformed by electroporation into NZ9000 and screened by colony PCR, prior to restriction and sequencing analyses. Similarly, Tuc2009 orf40 was amplified using orf40X-F and orf40X-R, and cloned into the BamHI and SpeI sites of pTX8048. The restriction site BamHI in pTX8048 but also pTX8049 allows the in-frame cloning of a gene of interest, as shown in Figure 1 . The three genes encoding the components of the Tuc2009 phage baseplate, i.e. $b b p U, b p p A$ and $b p p L$, were amplified from Tuc2009 DNA and flanked with a C-terminal hexa-histidine tag using primers UAL-F and UAL-R. The PCR product was digested with NcoI and

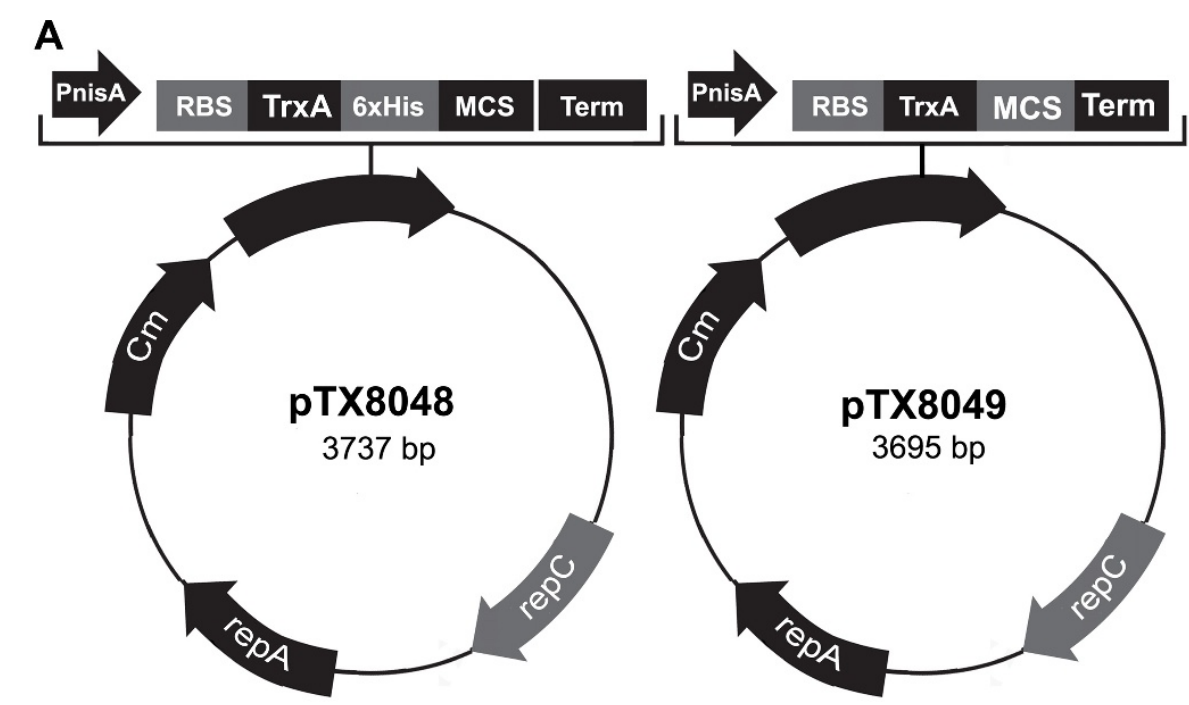

B

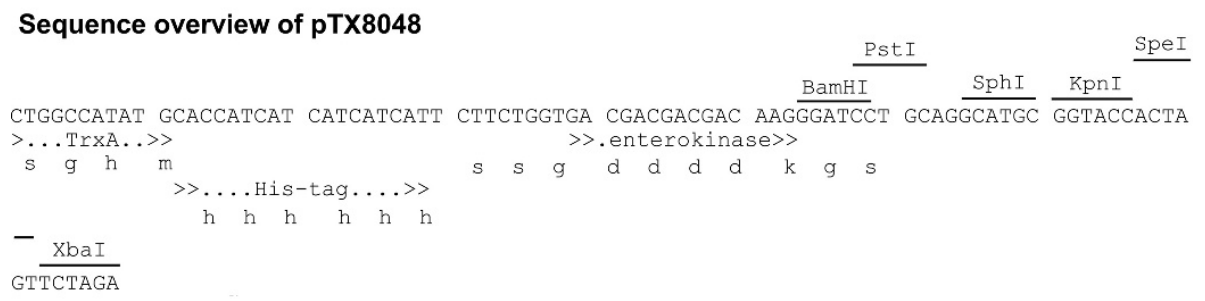

Sequence overview of pTX8049

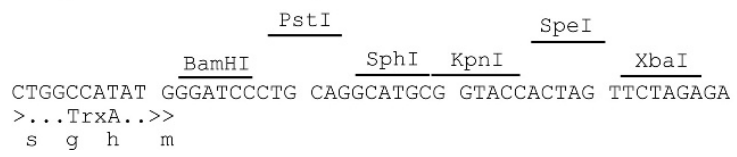

Figure 1 Maps and sequence overview of pTX8048 and pTX8049. (A) Vector maps of pTX8048 and pTX8049, which were constructed by insertion of the E. coli thioredoxin gene trxA, an enterokinase-specific cleavage site and a hexahistidine-tag as illustrated; (B) DNA sequence overview of the multiple cloning sites of pTX8048 and pTX8049. PnisA, nisin-inducible promoter; RBS, ribosome binding site; trXA, E. coli thioredoxin A-encoding gene; MCS, multiple cloning site; term, transcriptional terminator; Cm, chloramphenicol cassette. All restriction sites shown here are unique and can be used as cloning sites. The restriction site BamHI in pTX8048 and pTX8049 allows the in-frame cloning of the gene of interest. 
SpeI, and cloned into pNZ8048 cut with NcoI and SpeI. Similarly, the DNA region encompassing $b p p U, \quad b p p A$ and $b p p L$ was amplified using UALX-F and UALX-R, and then cloned into the BamHI and SpeI sites of pTX8048. The gene encoding the Bbr_0140 gene product was amplified from Bifidobacterium breve UCC2003 genomic DNA [30] and flanked with either a $\mathrm{C}$ - or an N-terminal hexa-histidine-encoding tag using, respectively, primer combinations $0140 \mathrm{C}-\mathrm{F}$ and $0140 \mathrm{C}$ $\mathrm{R}$, or $0140 \mathrm{~N}-\mathrm{F}$ and $0140 \mathrm{~N}-\mathrm{R}$. The PCR product was digested with NcoI and XbaI, and cloned into pNZ8048 cut with NcoI and XbaI. Similarly, Bbr_O140 was amplified using 0140X-F and 0140X-R, and subsequently cloned into BamHI and XbaI-restricted pTX8048.

\section{Protein expression assay}

L. lactis NZ9000 cells harbouring one of the various plasmid constructs described in the Methods section were propagated overnight at $30^{\circ} \mathrm{C}$ in M17 broth [25] containing $0.5 \%(\mathrm{w} / \mathrm{v}) \mathrm{D}$-glucose and supplemented with $5 \mu \mathrm{g} / \mathrm{ml}$ chloramphenicol. Fresh GM17 media supplemented with $5 \mu \mathrm{g} / \mathrm{ml}$ chloramphenicol was inoculated with a $1 / 50(\mathrm{v} / \mathrm{v})$ overnight liquid culture and incubated at $30^{\circ} \mathrm{C}$. When the optical density at $600 \mathrm{~nm}$ reached 0.4 , protein expression was induced by the addition of nisin to a final concentration of $0.2 \%(\mathrm{v} / \mathrm{v})$ [31]. Liquid culture was further incubated at $30^{\circ} \mathrm{C}$ for 4 hours and bacterial cells were harvested by centrifugation $(3000 \times$ $\mathrm{g}$ for $20 \mathrm{~min}$ at $4^{\circ} \mathrm{C}$ ). Bacterial cell pellets were washed in $50 \mathrm{mM} \mathrm{NaH} \mathrm{PO}_{4}, 300 \mathrm{mM} \mathrm{NaCl}, 10 \mathrm{mM}$ imidazole, $\mathrm{pH} 8.0$ and stored at $-80^{\circ} \mathrm{C}$ until further use [31].

\section{Fractionation, SDS-PAGE, immunoblotting analysis and protein assays}

Protein samples were prepared as described by BaheyEl-Din et al. [31]. Bacterial pellets were resuspended in $50 \mathrm{mM} \mathrm{NaH} \mathrm{PO}_{4}, 300 \mathrm{mM} \mathrm{NaCl}, 10 \mathrm{mM}$ imidazole, pH 8.0 supplemented with $30 \mathrm{mg} / \mathrm{ml}$ lysozyme and incubated for $30 \mathrm{~min}$ on ice. Cell preparations were then sonicated $(8 \times 10 \mathrm{sec}$ with $10 \mathrm{sec}$ on ice between each cycle) at maximum amplitude (MSE Soniprep 150, Sanyo). Insoluble and soluble fractions were separated by centrifugation at $14,000 \times \mathrm{g}$ for $10 \mathrm{~min}$ at $4{ }^{\circ} \mathrm{C}$ and stored at $-20^{\circ} \mathrm{C}$ for further analysis. Sodium dodecyl sulfate-polyacrylamide gel electrophoresis (SDS-PAGE) was performed as previously described [32]. Proteins from $12.5 \%$ acrylamide gels were then transferred onto a PVD membrane (Millipore, UK) by electroblotting [33]. Mouse polyclonal antibodies directed against the polyhistidine tag or rabbit polyclonal antibodies directed against $\mathrm{BppU}$, BppA and BppL were used as primary antibody [26]. Monoclonal anti-mouse or anti-rabbit antibodies coupled to horseradish-peroxidase (Sigma, USA) were used as secondary antibody. The membrane was developed using hydrogen peroxide and 4-chloro-1naphthol (Sigma). His-tagged proteins were purified using the PrepEase ${ }^{\circledR}$ Histidine-tagged Protein Purification kit (USB, OH, USA). Protein content was measured using the Bio-Rad Protein Assay (Germany), based on the Bradford protein quantification method.

\section{Enzymatic cleavage of TrxA fusion proteins using enterokinase}

The fusion protein TrxA-Bbr_0140 was expressed and His-tagged purified as described above. Purified enterokinase from calf intestine (Roche $\mathrm{GmbH}$, Germany) was used to cleave TrxA-Bbr_0140 according to manufacturer's instructions. TrxA-Bbr_0140 was dialyzed against $50 \mathrm{mM}$ Tris buffer, $\mathrm{pH}$ 8.0, since phosphate buffer is known to significantly reduce enterokinase activity as indicated in the user's manual. Typically, $25 \mu \mathrm{g}$ TrxABbr_0140 was incubated with $0.6 \mu \mathrm{g}$ enterokinase for 16 $\mathrm{h}$ at $20^{\circ} \mathrm{C}$ or $37^{\circ} \mathrm{C}$ (enterokinase: TrxA-Bbr_0140 ratio $=$ $1: 42$ ). We tested the effect of SDS on enterokinase cleavage efficiency as recommended in the manufacturer's manual, by supplementing the reaction mixture with $0.1 \%(\mathrm{w} / \mathrm{v})$ SDS. An equal volume of $2 \mathrm{X}$ SDS-PAGE loading buffer was added and the samples were boiled at $95^{\circ} \mathrm{C}$ for $5 \mathrm{~min}$ to inactivate enterokinase. The cleaved protein products were analyzed by SDS-PAGE.

\section{Results and discussion}

\section{Description of the two L. lactis thioredoxin-fusion expression vectors}

The two L. lactis thioredoxin-fusion expression vectors, called pTX8048 and pTX8049 (Figure 1) were employed in an attempt to express a number of proteins encoded by the lactococcal phage Tuc2009 and B. breve UCC2003. The anticipated translational fusions in both plasmids are placed under the transcriptional control of the nisin-inducible promoter Pnis $A$, ensuring a tight control of protein expression in L. lactis [3]. The original ribosome binding site present in plasmid pNZ8048 was retained to ensure efficient translation of the fusion protein (Figure 1) as it had previously been reported that low expression of proteins may be due to inefficient translational initiation of mRNA [34]. The E. coli thioredoxin $\operatorname{trx} A$ represents the $\mathrm{N}$-terminal portion of the fusion protein (Figure 1), promoting an efficient initiation of translation as previously described [13]. In addition, plasmid pTX8048 has been designed to join the thioredoxin $\mathrm{C}$-terminus to the recombinant protein $\mathrm{N}$ terminus with an amino-acid linker (SSGDDDDKGS) adapted from LaVallie et al. [19], consisting of serine $(\mathrm{S})$, glycine $(\mathrm{G})$, aspartic acid (D) and lysine (K) residues and a highly-specific enterokinase cleavage site (DDDDK) previously used in an E. coli thioredoxin fusion system [19] (Figure 1). The $(\mathrm{SSG}) \mathrm{X}_{5}(\mathrm{GS})$ residues 
act as flexible joints within the fusion protein connecting the thioredoxin $\mathrm{C}$-terminus to the recombinant protein $\mathrm{N}$-terminus. It facilitates access to the enterokinase cleavage site (DDDDK), to facilitate release of the mature protein [35]. In pTX8048, the thioredoxin-specifying sequence was modified to include a C-terminal hexa-histidine encoding tag, also termed 'Histidinepatch thioredoxin' in the originally developed E. coli fusion expression systems [36,37] enabling the purification of the fusion protein by Ni-TED affinity chromatography. The thioredoxin and the hexa histidine-tag are located upstream of the enterokinase cleavage site and can therefore be removed from the protein of interest (Figure 1). In comparison, pTX8049 only contains the $E$. coli thioredoxin gene trxA followed by a multiple cloning site to insert a gene of interest in an in-frame manner (Figure 1). The lack of additional purification tags or linkers in PTX8049 allows a greater level of flexibility in designing and constructing original fusion proteins, $i$. $e$. addition, choice and location of purification tags [13], peptide linkers [38] and specific cleavage sites (tobacco etch virus protease cleavage site, thrombin or factor $\mathrm{Xa}$ ) [35] (Figure 1). Methods and performances to over-produce proteins using pTX8049 are identical to pTX8048, as they both share the same pNZ8048 backbone and range of bacterial expression hosts.

\section{Production of Tuc2009 ORF40 as a fusion protein}

In $E$. coli but also in L. lactis, the production of small proteins or peptides is often problematic, as proteins can be subject to degradation or can aggregate into inclusion bodies. Tuc2009 ORF40 is a small protein $(7.65 \mathrm{kDa})$ with no known function and encoded by the lactococcal phage Tuc2009. We initially attempted to express the C-terminal His-tagged Tuc2009 ORF40 using the vector pNZ8048 in which ORF40 was cloned. The size of Tuc2009 ORF40 does not allow its detection by SDS-PAGE as the corresponding band would have been masked by the large amount of lyzozyme $(14 \mathrm{kDa})$ required to lyse L. lactis NZ9000 (Figure 2, panel A). However, further immunoblotting analysis and Ni-TED affinity chromatography indicated that Tuc2009 ORF40 was not expressed in either soluble or insoluble form in NZ9000 (data not shown). We constructed the vector pTX8048-40 to express the fusion protein TrxATuc2009 ORF40. Expression assays of TrxA-ORF40 in NZ9000 are shown in Figure 2. A distinct band corresponding to TrxA-ORF40 (21.8 kDa) was observed in the soluble fraction (Figure 2, panel A). Subsequently, TrxA-ORF40 was successfully purified by Ni-TED chromatography - availing of the peptide linker of pTX8048 containing a His-tag patch - and the total soluble fraction was analyzed by immunoblotting using anti-poly histidine antibodies (Figure 2, panels B and C). Using the thioredoxin fusion gene expression vector pTX8048, similar results were obtained for other small phage proteins, such as Tuc2009 ORF41 (12.8 kDa) and Tuc2009 ORF43 (11.9 kDa), where initial expression attempts using the original pNZ8048 NICE vector had also failed (data not shown). These results clearly demonstrate that small proteins when fused to the $E$. coli thioredoxin can be efficiently expressed in $L$. lactis.

\section{Production and purification of the Tuc2009 phage baseplate in L. lactis NZ9000}

Recombinant proteins may be improperly folded, preventing interactions with their protein partner(s). Such problems hamper further characterization of large

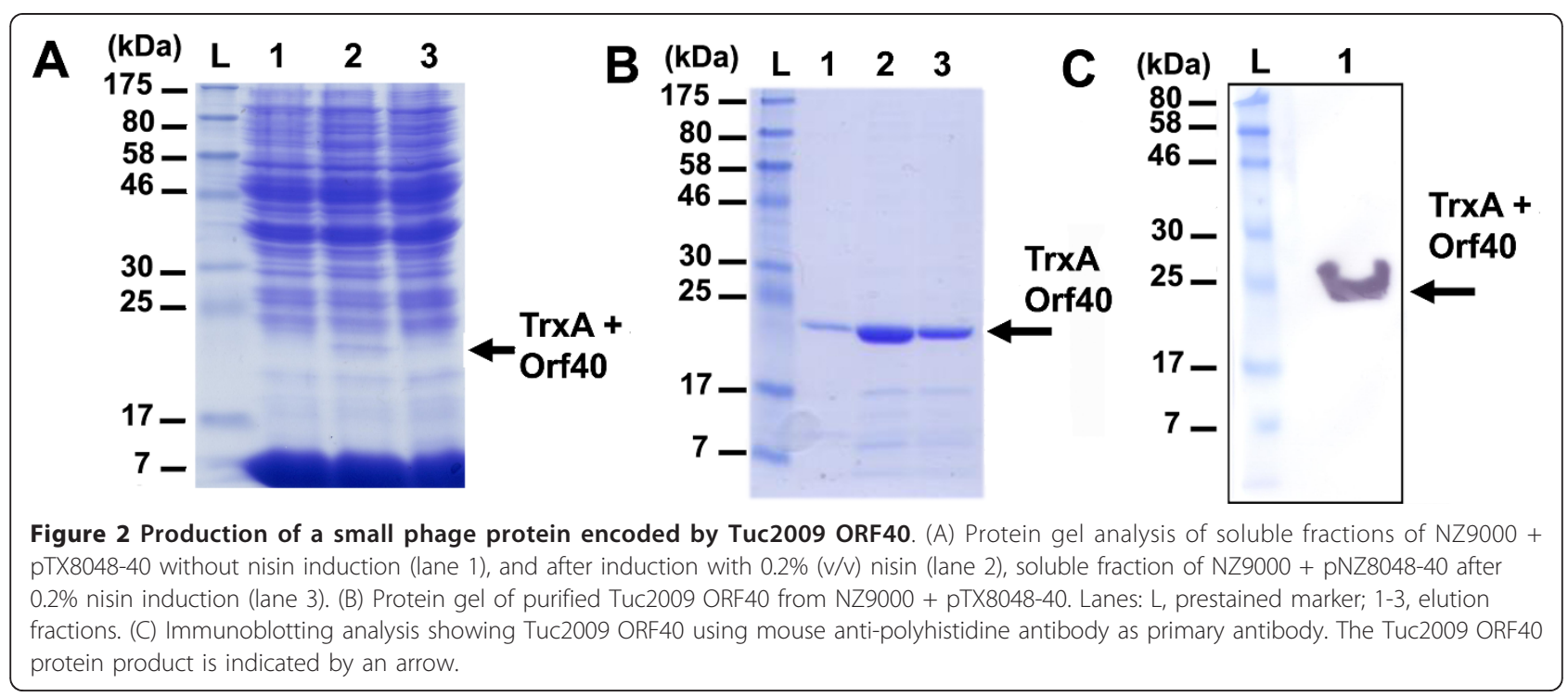


hetero(multi)meric protein complexes, as certain protein-protein interactions may be prevented. The baseplate (Bpp) of Tuc2009 is a large multimeric protein complex involved in host recognition [39-43]. It consists of three proteins: the upper baseplate (BppU), the associated baseplate (BppA) and the lower baseplate (BppL) $[26,41]$. Although a low-resolution model of the Bpp complex has been proposed [41], the fine details of its intimate structure are not yet fully understood. Further functional and structural analyses of Bpp would be greatly facilitated if the Bpp complex could be overexpressed. Initial attempts to over-express the Bpp complex in L. lactis using the vector pNZ8048 in which the corresponding genes of the Bpp complex had been cloned demonstrated that BppU, BppA and BppL were produced, although at low levels. However, subsequent purification attempts did not allow the co-purification of the three Bpp complex components, i.e. BppU, BppA and BppL (data not shown). In Tuc2009 and also the closely related lactococcal phage TP901-1, the baseplate complex is associated with the initiation complex and the baseplate component BppU has been reported to be particularly vulnerable to degradation [41]. It was hoped that production of the Bpp complex, where BppU is fused to thioredoxin, would stabilize the Bpp complex, and that the presence of the His-tag in the peptide linker would facilitate co-purification of the heteromeric Bpp complex. In order to test this idea, plasmid pTX8048-UAL was generated and tested for Bpp complex expression and purification. Following induction, and cell lysis, total soluble protein fraction was resolved by SDS-PAGE (Figure 3). Although only one band corresponding to $\mathrm{BppL}(18.8 \mathrm{kDa})$ was visually detected in this way, further purification and immunoblotting

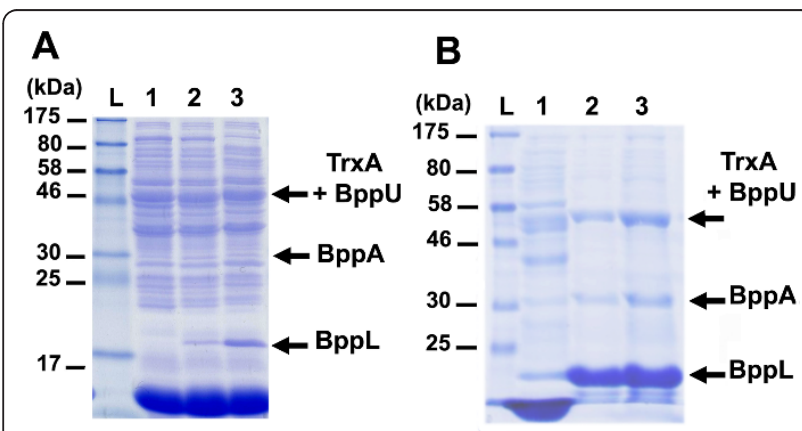

Figure 3 Co-production of the Tuc2009 baseplate components BppU, BppA and BppL. (A) Protein gel analysis of soluble fractions of NZ9000 + pTX8048-UAL without nisin induction (lane1), NZ9000 + pNZ8048-UAL following induction with 0.2\% (v/v) nisin (lane 2) and NZ9000 + pTX8048-UAL following induction with $0.2 \%(\mathrm{~V} / \mathrm{V})$ nisin (lane 3). (B) Protein gel of Ni-affinity purified baseplate complex from NZ9000 + pTX8048-UAL soluble fraction. Lanes: L, prestained marker; 1, flow-through; 2-3, elution fractions. analyses indicated that $\operatorname{TrxA}-\mathrm{BppU}(50.4 \mathrm{kDa})$ and BppA $(31.85 \mathrm{kDa})$ and $\mathrm{BppL}$ were all expressed and could be co-purified as a complex by affinity chromatography availing of the hexahistidine-tag of TrxA-BppU (Figures 3 and 4). Immunoblotting analysis was performed to check the integrity of the over-expressed proteins (Figure 4), which indicated the apparent absence of any degradation and/or sub-products. This result clearly demonstrated that the L. lactis Trx-fusion expression system is also suitable for the production and purification of intact heteromultimeric protein complexes.

\section{Over production of Bifidobacterium breve UCC2003 Bbr_0140 using pTX8048}

In an effort to demonstrate the versatility of our thioredoxin system, we also attempted to over-produce a protein encoded by a bacterium that is unrelated to $L$. lactis. Bbr_0140 specifies a 200 amino-acid protein (23.5 $\mathrm{kDa}$ ) encoded by the Bifidobacterium breve UCC2003 genome [30]. We initially attempted to express either Cor N-terminally His-tagged Bbr_0140 using the standard expression vector pNZ8048 in which we had cloned the coding sequence of Bbr_0140. However, using this expression system no Bbr_0140 protein product was detected by SDS-PAGE (Figure 5, panel A). We therefore constructed pTX8048-0140 to express the fusion protein TrxA-Bbr_0140 as described in Methods. Expression assays of TrxA-ORF40 in NZ9000 are shown in Figure 5. A distinct band corresponding to TrxABbr_0140 (37.5 kDa) was observed in the soluble fraction, clearly demonstrating that TrxA-Bbr_0140 was successfully over-produced, while further analysis showed that this protein could be purified by Ni-TED affinity chromatography and visualized by immunoblotting using anti-poly histidine antibodies as a primary antibody (Figure 5, panels B and C). These results show

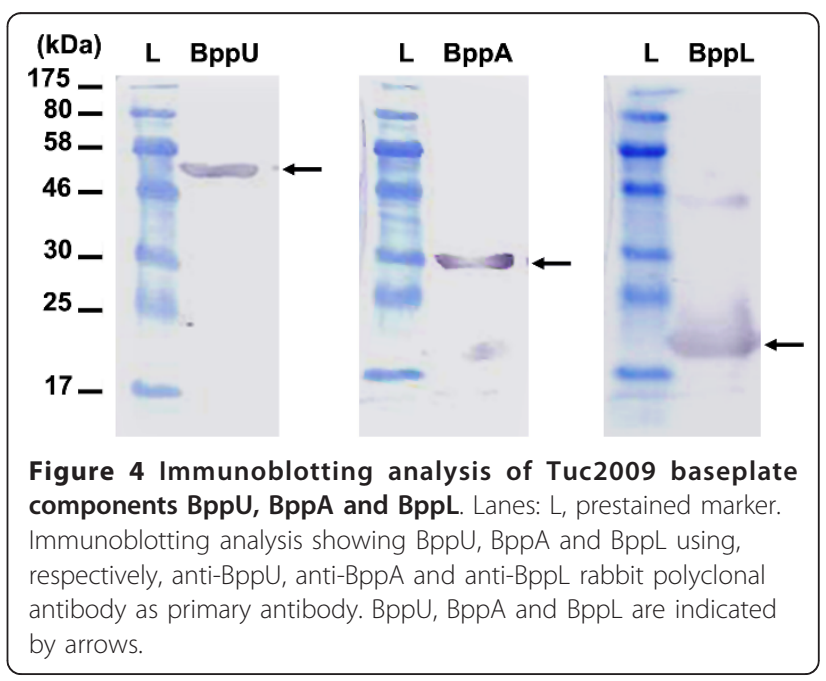




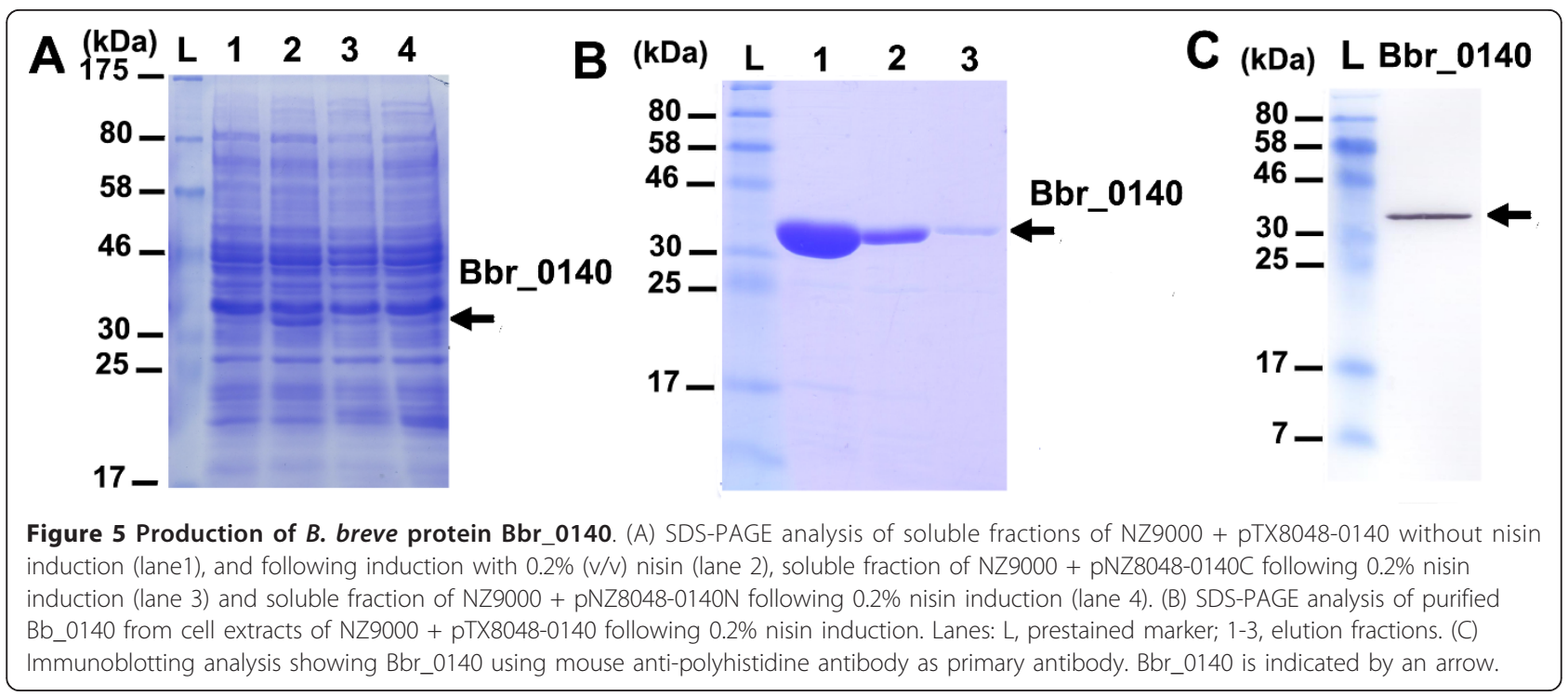

that the Trx-fusion expression system for L. lactis is also suitable to produce heterologous proteins from a completely unrelated bacterial origin.

\section{Enterokinase cleavage of the thioredoxin fusion protein TrxA-Bbr 0140}

The presence of a cleavage site is an important feature of this Trx-fusion expression system, as it allows the cleavage and release of the thioredoxin moiety from its fused protein of interest. Our vector pTX8048 possesses a peptide linker containing an enterokinase cleavage site (DDDDK) that connects the thioredoxin to the C-terminus of the fused protein. To test whether we could remove the Trx-moiety, purified thioredoxin-Bbr_0140 fusion protein was incubated with calf intestine enterokinase as described in the Methods section. As shown in Figure 6 (panel A), the thioredoxin-Bbr_0140 fusion protein was efficiently and specifically cleaved, as two products of $23.5 \mathrm{kDa}$ and $14 \mathrm{kDa}$ corresponding to the mature Bbr_0140 protein and the thioredoxin- linker product, respectively, were clearly observed by SDSPAGE. The supplementation of the cleavage mixture with $0.1 \%(\mathrm{w} / \mathrm{v})$ SDS did not improve the cleavage efficiency (Figure 6, panel A), indicating that the enterokinase cleavage site is equally accessible and cleavable in native and denaturing conditions. Further applications will dictate what cleavage conditions can be used. Under native conditions, subsequent purification of the cleaved Bbr_0140 protein was performed using Ni-TED chromatography. His-tagged thioredoxin-linker and uncleaved fusion proteins were retained on the nickel resins, whereas cleaved mature proteins were collected in the flow-through (Figure 6, panel B). However, the purified samples will still contain the enterokinase contaminant, although its corresponding band can not be observed on the protein gel (Figure 6, panel B). Additional/alternative chromatography techniques may be considered, such as ion exchange chromatography or gel filtration to further purify the mature protein following thioredoxin cleavage by removing the enterokinase contaminant [19]. Alternatively, the use of commercially available his-tagged enterokinase could also be considered and implemented to the purification procedure described in this study. Using the Bio Rad Protein Quantification Assay, we measured an average yield of $1.2 \mathrm{mg}$ per litre of culture of purified Bbr_0140. It is noteworthy that protein yields are protein-dependent and not every protein will be expressed at the same level using pTX8048 and pTX8049. Mierau and colleagues previously reported that the original NICE system allows the production of

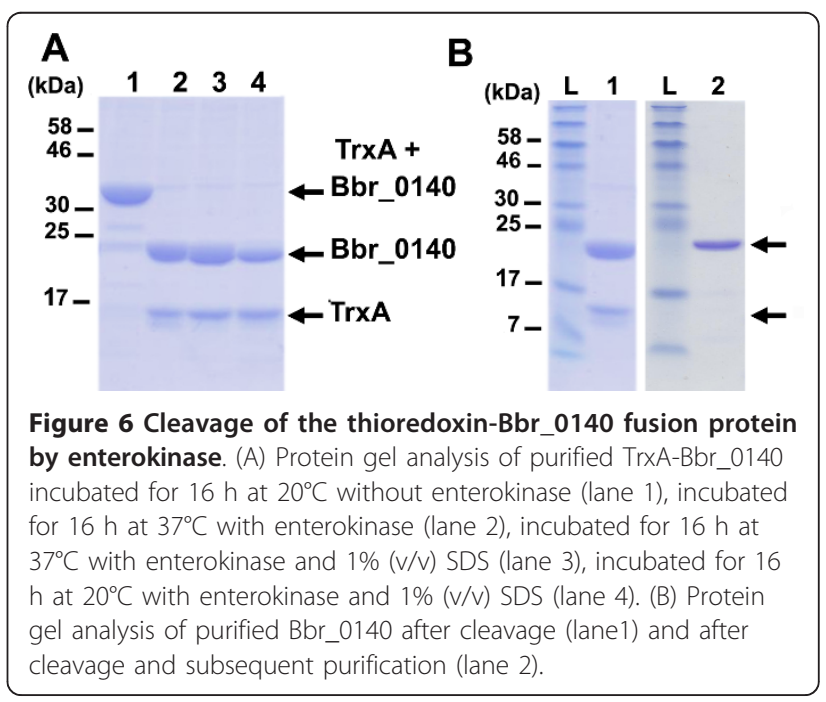


very high levels of proteins, e.g. up to $300 \mathrm{mg}$ of lysostaphin per liter of culture on a industrial scale [1]. Although the yields of production shown are significantly lower using our thioredoxin gene fusion systems, it is still a valuable tool as it allows the expression of soluble proteins that could not be expressed with the original NICE system. Also, the adjustment of key protein-specific parameters, such as medium composition and fermentation conditions could significantly improve the production yield of the target protein. The design and incorporation of an enterokinase cleavage site in pTX8048 is shown to be functional and further purification allows the final production of native and soluble heterologous proteins in L. lactis.

\section{Conclusions}

The thioredoxin gene fusion system represents an attractive system to over-produce and purify proteins in L. lactis that exhibit poor or no expression, or produce insoluble proteins using conventional expression vectors. In this study, we have described the construction of an L. lactis Trx-fusion expression system and demonstrated its applicability by over-producing and purifying various proteins or complexes as soluble thioredoxin fusions. The benefits of the original $E$. coli thioredoxin fusion expression system have previously been demonstrated $[18,19]$, and in this report we have shown that these are also applicable to the expression host L. lactis, when combined with the NICE system. This expression and purification tool offers a wide spectrum of applications in L. lactis and also other Gram-positive bacteria that can accommodate the NICE system, such as L. plantarum [44]. Although our study does not show the functionality of the overexpressed proteins, we are confident that the majority of such proteins are biologically active as based on numerous peer-reviewed studies using the original NICE system, as reviewed by Mierau et al. [1]. The protein production levels obtained in L. lactis using the thioredoxin fusion gene expression system allow further structural and biochemical analysis, such as Xray crystallography analysis, antibody production, protein-protein interaction assays, and enzymatic assays.

\section{Acknowledgements}

The study described in this manuscript is supported by D. van Sinderen's Science Foundation Ireland Principal Investigator grant (Ref. No. 08/IN.1/ B1909).

\footnotetext{
Author details

${ }^{1}$ Department of Microbiology, University College Cork, Cork, Ireland.

${ }^{2}$ Alimentary Pharmabiotic Centre, University College Cork, Cork, Ireland. ${ }^{3}$ Architecture et Fonction des Macromolécules Biologiques, UMR 6098 Centre National de la Recherche Scientifique and Universités d'Aix-Marseille I \& II, Campus de Luminy, Case 932, 13288 Marseille Cedex 09, France. ${ }^{4}$ Department of Veterinary Sciences, University of Helsinki, Agnes Sjöbergin katu 2, 00790 Helsinki, Finland.
}

\section{Authors' contributions}

FPD performed all experiments described in this study, designed the different expression vectors and drafted the manuscript, except MOCM who performed cloning and protein production of Bbr_0140 proteins. CC participated in its design and its coordination. FDP and DVS conceived of the study, and participated in its design and coordination and wrote the manuscript. All authors read, edited and approved the final manuscript.

\section{Competing interests}

The authors declare that they have no competing interests.

Received: 6 June 2011 Accepted: 9 August 2011

Published: 9 August 2011

\section{References}

1. Mierau I, Kleerebezem M: 10 years of the nisin-controlled gene expression system (NICE) in Lactococcus lactis. Applied Microbiology and Biotechnology 2005, 68(6):705-717.

2. Kuipers OP, Beerthuyzen MM, de Ruyter PGGA, Luesink EJ, de Vos WM: Autoregulation of nisin biosynthesis in Lactococcus lactis by signal transduction. Journal of Biological Chemistry 1995, 270(45):27299-27304.

3. Kuipers OP, de Ruyter PGGA, Kleerebezem M, de Vos WM: Quorum sensing-controlled gene expression in lactic acid bacteria. Journal of Biotechnology 1998, 64(1):15-21.

4. Rigoulay C, Poquet I, Madsen SM, Gruss A: Expression of the Staphylococcus aureus surface proteins HtrA1 and HtrA2 in Lactococcus lactis. FEMS Microbiology Letters 2004, 237(2):279-288.

5. Burgess C, O'Connell-Motherway M, Sybesma W, Hugenholtz J, van Sinderen D: Riboflavin production in Lactococcus lactis: potential for in situ production of vitamin-enriched foods. Applied and Environmental Microbiology 2004, 70(10):5769-5777.

6. Kunji ERS, Slotboom D-J, Poolman B: Lactococcus lactis as host for overproduction of functional membrane proteins. Biochimica et Biophysica Acta (BBA) - Biomembranes 2003, 1610(1):97-108.

7. Kuipers OP, Beerthuyzen MM, Siezen RJ, de Vos WM: Characterization of the nisin gene cluster nisABTCIPR of Lactococcus lactis. European Journal of Biochemistry 1993, 216(1):281-291.

8. Hasper HE, de Kruijff B, Breukink E: Assembly and stability of nisin Lipid II Pores. Biochemistry 2004, 43(36):11567-11575.

9. Hickey RM, Ross RP, Hill C: Controlled autolysis and enzyme release in a recombinant lactococcal strain expressing the metalloendopeptidase enterolysin A. Appl Environ Microbiol 2004, 70(3):1744-1748.

10. Ruyter PGGAd, Kuipers OP, Meijer WC, Vos WMd: Food-grade controlled lysis of Lactococcus lactis for accelerated cheese ripening. Nature Biotechnology 1997, 15(10):976-979.

11. Baneyx F: Recombinant protein expression in Escherichia coli. Current Opinion in Biotechnology 1999, 10(5):411-421.

12. Vincentelli R, Bignon C, Gruez A, Canaan S, Sulzenbacher G, Tegoni M Campanacci V, Cambillau C: Medium-scale structural genomics: strategies for protein expression and crystallization. Chem Inform 2003, 34(20):no-no.

13. LaVallie ER, McCoy JM: Gene fusion expression systems in Escherichia coli. Current Opinion in Biotechnology 1995, 6(5):501-506.

14. Smith DB, Johnson KS: Single-step purification of polypeptides expressed in Escherichia coli as fusions with glutathione S-transferase. Gene 1988, 67(1):31-40.

15. di Guana C, Lib P, Riggsa PD, Inouyeb H: Vectors that facilitate the expression and purification of foreign peptides in Escherichia coli by fusion to maltose-binding protein. Gene 1988, 67(1):21-30.

16. Nilsson B, Abrahmsén L, David VG: Fusions to staphylococcal protein A. In Methods in Enzymology. Volume 185. Academic Press; 1990:144-161.

17. Davis GD, Elisee C, Newham DM, Harrison RG: New fusion protein systems designed to give soluble expression in Escherichia coli. Biotechnology and Bioengineering 1999, 65(4):382-388.

18. LaVallie ER, Lu Z, Diblasio-Smith EA, Collins-Racie LA, McCoy JM, Jeremy Thorner SDEJNA: Thioredoxin as a fusion partner for production of soluble recombinant proteins in Escherichia coli. In Methods in Enzymology. Volume 326. Academic Press; 2000:322-340.

19. LaVallie ER, DiBlasio EA, Kovacic S, Grant KL, Schendel PF, McCoy JM: A thioredoxin gene fusion expression system that circumvents inclusion body formation in the E. coli cytoplasm. Nature Biotechnology 1993, 11(2):187-193. 
20. Waugh DS: Making the most of affinity tags. Trends in Biotechnology 2005, 23(6):316-320

21. Esposito D, Chatterjee DK: Enhancement of soluble protein expression through the use of fusion tags. Current Opinion in Biotechnology 2006, 17(4):353-358.

22. Hu Y-c: Baculovirus as a highly efficient expression vector in insect and mammalian cells. Acta Pharmacol Sin 2005, 26(4):405-416.

23. Daly R, Hearn MTW: Expression of heterologous proteins in Pichia pastoris: a useful experimental tool in protein engineering and production. Journal of Molecular Recognition 2005, 18(2):119-138.

24. Dickason RR, Edwards RA, Bryan J, Huston DP: Versatile E. coli thioredoxin specific monoclonal antibodies afford convenient analysis and purification of prokaryote expressed soluble fusion protein. Journal of Immunological Methods 1995, 185(2):237-244.

25. Terzaghi BE, Sandine WE: Improved medium for lactic streptococci and their bacteriophages. Appl Environ Microbiol 1975, 29(6):807-813.

26. Mc Grath S, Neve H, Seegers JF, Eijlander R, Vegge CS, Brondsted L, Heller KJ, Fitzgerald GF, Vogensen FK, van Sinderen D: Anatomy of a lactococcal phage tail. J Bacteriol 2006, 188(11):3972-3982.

27. Maze A, O'Connell-Motherway M, Fitzgerald GF, Deutscher J, van Sinderen D: Identification and characterization of a fructose phosphotransferase system in Bifidobacterium breve UCC2003. Appl Environ Microbiol 2007, 73(2):545-553.

28. Holo H, Nes IF: High-frequency transformation, by electroporation, of Lactococcus lactis subsp. cremoris grown with glycine in osmotically stabilized media. Appl Environ Microbiol 1989, 55(12):3119-3123.

29. Seegers JFML, Mc Grath S, O'Connell-Motherway M, Arendt EK, van de Guchte M, Creaven M, Fitzgerald GF, van Sinderen D: Molecular and transcriptional analysis of the temperate lactococcal bacteriophage Tuc2009. Virology 2004, 329(1):40-52.

30. O'Connell Motherway M, Zomer A, Leahy SC, Reunanen J, Bottacini F, Claesson MJ, O'Brien F, Flynn K, Casey PG, Moreno Munoz JA, et al: Functional genome analysis of Bifidobacterium breve UCC2003 reveals type IVb tight adherence (Tad) pili as an essential and conserved hostcolonization factor. Proceedings of the National Academy of Sciences 108(27):11217-11222

31. Bahey-El-Din M, Griffin BT, Gahan CG: Nisin inducible production of listeriolysin O in Lactococcus lactis NZ9000. Microbial Cell Factories 2008, $7: 24$.

32. Sambrook J, Fritsch EF, Maniatis T: Molecular cloning: a laboratory manual. Cold Spring Harbor, NY: Cold Spring Harbor Laboratory Press; 21989.

33. Towbin H, Staehelin T, Gordon J: Electrophoretic transfer of proteins from polyacrylamide gels to nitrocellulose sheets: procedure and some applications. Proc Natl Acad Sci USA 1979, 76(9):4350-4354.

34. Stormo GD, Schneider TD, Gold LM: Characterization of translational initiation sites in E. coli. Nucleic Acids Research 1982, 10(9):2971-2996.

35. LaVallie ER, McCoy JM, Smith DB, Riggs P: Enzymatic and chemical cleavage of fusion proteins. John Wiley \& Sons, Inc.; 2001.

36. McCoy J, LaVallie E: Expression and purification of thioredoxin fusion proteins. John Wiley \& Sons, Inc.; 2001.

37. Lu Z, DiBlasio-Smith EA, Grant KL, Warne NW, LaVallie ER, Collins-Racie LA, Follettie MT, Williamson MJ, McCoy JM: Histidine patch thioredoxins: mutant forms of thioredoxin with metal chelating affinity which provide for convenient purifications of thioredoxin fusion proteins. Journal of Biological Chemistry 1996, 271(9):5059-5065.

38. Arai $R$, Ueda H, Kitayama A, Kamiya N, Nagamune T: Design of the linkers which effectively separate domains of a bifunctional fusion protein. Protein Engineering 2001, 14(8):529-532.

39. Siponen M, Spinelli S, Blangy S, Moineau S, Cambillau C, Campanacci V: Crystal structure of a chimeric receptor binding protein constructed from two lactococcal phages. J Bacterio/ 2009, 191(10):3220-3225.

40. Spinelli S, Campanacci V, Blangy S, Moineau S, Tegoni M, Cambillau C: Modular structure of the receptor binding proteins of Lactococcus lactis phages. Journal of Biological Chemistry 2006, 281(20):14256-14262.

41. Sciara G, Blangy S, Siponen M, Mc Grath S, van Sinderen D, Tegoni M, Cambillau C, Campanacci V: A topological model of the baseplate of lactococcal phage Tuc2009. Journal of Biological Chemistry 2008, 283(5):2716-2723.

42. Vegge CS, Brondsted L, Neve H, Mc Grath S, van Sinderen D, Vogensen FK: Structural characterization and assembly of the distal tail structure of the temperate lactococcal bacteriophage TP901-1. J Bacteriol 2005, 187(12):4187-4197.

43. Vegge CS, Vogensen FK, Mc Grath S, Neve H, van Sinderen D, Brondsted L Identification of the lower baseplate protein as the antireceptor of the temperate lactococcal bacteriophages TP901-1 and Tuc2009. J Bacteriol 2006, 188(1):55-63.

44. Serrano LM, Molenaar D, Wels M, Teusink B, Bron P, de Vos W, Smid E: Thioredoxin reductase is a key factor in the oxidative stress response of Lactobacillus plantarum WCFS1. Microbial Cell Factories 2007, 6(1):29.

doi:10.1186/1475-2859-10-66

Cite this article as: Douillard et al:: Expanding the molecular toolbox for Lactococcus lactis: construction of an inducible thioredoxin gene fusion expression system. Microbial Cell Factories 2011 10:66.

\section{Submit your next manuscript to BioMed Central and take full advantage of:}

- Convenient online submission

- Thorough peer review

- No space constraints or color figure charges

- Immediate publication on acceptance

- Inclusion in PubMed, CAS, Scopus and Google Scholar

- Research which is freely available for redistribution 